\title{
$\angle S$ Research Square \\ The Association of Food Insecurity With Diabetes Control and Self-care in Diabetes Type 2 Patients
}

marjan mohammadi

Islamic Azad University Science and Research Branch

Seyyed Abolghasem Djazayeri

Tehran University of Medical Sciences

Asal Ataie-Jafari ( $\nabla$ asal_ataie2003@yahoo.com )

Research

Keywords: Food insecurity, type2 diabetes, glycemic control, self-care

Posted Date: June 10th, 2020

DOI: https://doi.org/10.21203/rs.3.rs-32268/v1

License: @ (i) This work is licensed under a Creative Commons Attribution 4.0 International License.

Read Full License 


\section{Abstract}

Background: Food insecurity can increase risks of health and nutritional problems, leading to difficulties in self-care and poor glycemic control in diabetic patients.

Purpose: This study assessed food insecurity and its association with diabetes control and self-care in type 2 diabetes patients.

Methods: In this cross sectional study, 148 adults with type 2 diabetes participated. Food insecurity and self-care were determined using the 18-item USDA household food security status questionnaire and selfcare (SDSCA) questionnaire. Data were analyzed using logistic and linear regression tests (SPSS 20 software).

Results: Thirty-seven percent of the participants were food-insecure and significantly more likely than food-secure participants to have poor glycemic control (OR=3.02; $\mathrm{Cl}$ : 1.45-2.65). No significant association was found between food-insecurity and overall self-care score.

Conclusion: Food-insecurity was directly associated with poor glycemic control in type 2 diabetes patients. Since economic status was significantly better in the food-secure group, it can be postulated that financial problems will eventually lead to poor glycemic control.Policy strategies to increaseaccess to diabetes-appropriate foods mayreduce socioeconomic inequalities in glycemiccontrol.

\section{Introduction}

Food insecurity is defined as "limited or unreliable access to adequate and healthy food in terms of nutritional value or limited ability to access acceptable foods in appropriate social ways" (1-3).

According to studies in various countries, the percentage of food insecurity in the United States is $14.7 \%$, Canada 10\%, Malaysia 50\%, Indonesia 11\%, the Philippines 35\%, Bolivia 70\%, Burkina Faso $73 \%$, Finland $5.7 \%$, and Pakistan 43\% (3-9). In Iran, an insecurity study based on household costs showed that 20 percent of the population did not have economic access to abdominal satiety, and about 50 percent had problems in meeting their cellular satiety (10).

Limited financial resources among insecure families leads to the purchase of cheaper, higher-calorie foods that are associated with weight gain and susceptibility to chronic diseases, including type 2 diabetes (11-13). The chronic and costly nature of diabetes imposes a heavy financial burden on society, with the cost of health care for a diabetic being about 4.6 times that of a non-diabetic (14). ADA announced in 2003 that after 2000, 1 in 3 Americans would develop diabetes during their lifetime. According to estimates by the World Health Organization (WHO), the prevalence of diabetes in Iran between 1995 and 2000 was about 5.5 to 5.7 percent; reaching 6.8 percent by 2025 (15).

People with food insecurity are at risk for diets that are less varied and of lower quality, insufficient intake of micronutrients, iron deficiency anemia, and low consumption of fruits and vegetables (16-20). Food 
insecurity also interferes with self-care advice for diabetes (21). Researchers have always reported a relationship between food insecurity and low self-esteem with diabetes control (21-24). Also, diabetic patients with food insecurity have higher A1c levels than those with food security (24-28). On the other hand, diabetics with food insecurity are also at risk for hypoglycemia (26).

In a study, it was shown that food insecurity was associated with poor glycemic control and had no significant relationship with self-care behaviors (29). In Iran, the relationship between food insecurity and diabetes has also been studied. In a study in Tehran, there was no significant relationship between food insecurity and blood sugar and lipid profile (30). In another study in newly diagnosed diabetic patients, as well as in a case-control study, a significant and direct relationship between food insecurity and diabetes control was observed $(31,32)$.

Given the limited studies in Iran and considering the relatively widespread prevalence of food insecurity $(26,33)$ and the growing prevalence of type 2 diabetes in Iranian society $(34)$, the present study aimed to investigate the status of food insecurity and its association with diabetes control and self-care in patients with type 2 diabetes.

\section{Materials \& Methods}

\section{Study Population}

This was a cross-sectional study on 148 type 2 diabetic patients between 30 and 65 years old, who had a medical record at Eghlid county Health Center and whose $\mathrm{HbA} 1 \mathrm{c}$ level were recorded during the last two weeks. Eghlid is a county in Fars Province in Southwest Iran. Patients were excluded if they any specific diseases (cardiovascular disease and stroke, cancer, acute kidney disease) were present, as well as pregnant and lactating women.

In the period of May to September of 2018, eligible patients were enrolled and the study procedure was explained for them on the phone. They were invited to three community health centers in Eghlid County to complete the questionnaires. Written consent was obtained and demographic questionnaire, food security questionnaire and self-care questionnaire were completed by patients with the supervision of nutritionists. The most recent $\mathrm{HbA} 1$ and fasting blood sugar (FBS) abstracted from the medical record and $\mathrm{HbA} 1 \mathrm{c} \geq 8.5 \%$ was classified as undesirable glycemic control. Weight and height were measured and BMI was calculated.

\section{Questionnaires}

A demographic questionnaire was used to collect general demographic information, including age, sex, ethnicity, education, and employment status. Household economic status was determined using a questionnaire including 9-item home appliances and was classified owning less than 3-item as poor economic level, 4 to 6-item as moderate economic level, and more than 7-item as wealthy economic level. 
The 18-item USDA household food security questionnaire was used to assess food security over the past 12 months (35). This questionnaire has been validated during previous studies in Iran (36). Rating of 18item USDA household food security status questionnaire was a below: positive rate to answers "often true", "sometimes true", "almost every month", "some months", and "yes" and zero score to responses "not true", "does not know or refused", "only 1 or 2 months", and "no". Finally, scores $0-2$ were categorized as food secure, scores 3-7 as food insecure without hunger, scores 8-12 as food insecure with moderate hunger, and scores 13 and higher as food insecure with severe hunger.

Collecting self-care behaviors was assessed using the Summary of Diabetes Self Care Activities (SDSCA) with 14 questions that assesses patients' self-care quality in the last seven days (37). Questions include diet: 5 questions, exercise: 2 questions, blood sugar control: 2 questions, foot care: 5 questions, and regular medications: 1 question. To score the questionnaire, for each question of self-care behaviors, one point was considered per day if it was done and zero points were considered if it was not done. The highest score in this tool is 98 , which indicates the highest quality of self-management. The validity and reliability of this questionnaire have been studied by Anbari et al (38).

Weight was measured using a Seca scale with an accuracy of $100 \mathrm{~g}$ with minimal coverage and no shoes, and height was measured by a tape without shoes with an accuracy of $0.1 \mathrm{~cm}$ by a nutritionist. BMI was calculated by dividing weight (in kilograms) by height squared (in square meters).

\section{Statistical Analyses}

All analyzes were performed using SPSS version 20 and the significance level was considered to be 0.05 . The relationship of food quality and self-care with food security was tested by linear regression analysis. Logistic regression was used to investigate the association between glycemic control and food security with a $95 \%$ confidence interval.

\section{Results}

Of the 155 eligible patients, 148 subjects completed the interviews. Findings of the food insecurity prevalence in diabetic participants are given in Table 1 . According to this table, $63 \%$ of households had food security, $23.9 \%$ had food insecurity without hunger, $10.2 \%$ had insecurity with moderate hunger, and $2.9 \%$ had insecurity with severe hunger. The majority of patients with good control had food security $(72.8 \%)$ and the majority of patients with poor diabetes control had some degrees of food insecurity (53.8\%). 
Table 1

Food security among at type 2 diabetes patients according to glycemic control status

\begin{tabular}{|c|c|c|c|c|}
\hline Food security status & glycemic control status & & & *p \\
\hline $\mathrm{HbA}_{1} \mathrm{C}<8.5 \%$ & $\mathrm{HbA}_{1} \mathrm{C} \geq 8.5 \%$ & Total & & \\
\hline (glycemic control) & (Poor glycemic control ) & & & \\
\hline Secure & $67(72.8)$ & $25(46.2)$ & $92(63)$ & 0.010 \\
\hline Insecure without starvation & $15(16.3)$ & $20(37)$ & $35(23.9)$ & \\
\hline Insecure whit moderate starvation & $8(8.6)$ & $7(12.9)$ & $15(10.2)$ & \\
\hline Insecure whit severe starvation & $2(2.3)$ & $2(3.9)$ & $4(2.9)$ & \\
\hline
\end{tabular}

Table 2 shows the characteristics of participants according to food security status. According to the table, there was a significant relationship between food security and marital status, so that the percentage of married people was higher in the food secure group than in insecure group. There was also a significant association between food security and economic status, education, $\mathrm{HbA} 1 \mathrm{c}$, and body mass index, with a higher percentage of poor, sub-diploma, patients with uncontrolled diabetes ( $\mathrm{HbA} 1 \mathrm{c} \geq 8.5 \%)$ and overweight and obese patients in the food insecure group compared with the secure group. Weight, body mass index, fasting blood sugar and $\mathrm{HbA1 \textrm {c }}$ were also significantly higher in the food insecure group than in the secure group. 
Table 2

patients' characteristics according to food security status

\section{Characteristics}

Age, mean \pm SD

Sex, n (\%)

Male

Female

Race, $\mathrm{n}(\%)$

Fars

Turkish and lorish

Education, $\mathrm{n}(\%)$

$<$ High school

$>$ High school

Economic status $\mathrm{n}(\%)$

Poor

Moderate

wealthy

Marital status, $\mathrm{n}(\%)$

Married

Single, divorced, widow

Employment status, n (\%)

Employed

Unemployed

Home ownership, n (\%)

Personal

Rental

Weight, mean \pm SD

Height, mean \pm SD
Food security status

Food security Food insecurity Total

$47 \pm 10$

$43 \pm 9$

$45.82 \pm 9.9$

0.223

$46(50)$

$24(44.4)$

$70(47.9)$

$76(52.1)$

$46950)$

$30(55.6)$

48 (88.8)

125 (85.6)

0.211

15 (16.3)

6 (11.2)

21 (14.4)

32 (34.7)

29 (53.8)

61(41.7)

0.040

$60(65.3)$

25 (46.2)

85 (58.3)

16 (17.4)

26 (48.2)

$42(28.8)$

48 (52.2)

22 (40.7)

70 (47.9)

0.000

$(4 / 30) 28$

$(1 / 11) 6$

34 (23.3)

85 (92.4)

42 (77.8)

127 (87)

0.048

7 (7.6)

12 (22.2)

19 (13)

45 (48.9)

25 (46.3)

70 (47.9)

0.180

47(51.1)

29 (53.7)

76 (52.1)

$63(68.5)$

39 (72.2)

$102(69.9)$

0.634

29 (31.5)

54 (27.8)

$44(30.1)$

70/50 (66-86)

$82.5(63-108)$

74 (52-119)

0.000

$163.74 \pm 9.17$

$171.72 \pm 10.5$

$166.69 \pm 10.3$

0.089 


\begin{tabular}{|c|c|c|c|c|}
\hline \multirow[t]{2}{*}{ Characteristics } & \multicolumn{3}{|c|}{ Food security status } & \multirow[t]{2}{*}{ P* } \\
\hline & Food security & Food insecurity & Total & \\
\hline \multicolumn{5}{|l|}{ BMI status, $\mathrm{n}(\%)$} \\
\hline Underweight & $6(6.5)$ & $2(3.9)$ & $8(5.5)$ & \\
\hline Normal weight & $46(50)$ & $6(11)$ & $52(35.6)$ & 0.030 \\
\hline Overweight & $34(37)$ & $27(50)$ & $61(41.8)$ & \\
\hline Obese & $6(6.5)$ & $19(35.1)$ & $25(17.1)$ & \\
\hline Waist circumference, mean \pm SD & $16.69 \pm 99.31$ & $17.32 \pm 96.82$ & $17.32 \pm 97.85$ & 0.199 \\
\hline $\mathrm{FBS}$, mean $\pm \mathrm{SD}$ & $168(128-282)$ & $198.5(127-325)$ & $179(126-321)$ & 0.010 \\
\hline \multicolumn{5}{|l|}{ Glycemic control, n (\%) } \\
\hline $\mathrm{HbA}_{1} \mathrm{C}<8.5 \%$ & $68(73.9)$ & $23(42.6)$ & $91(62.3)$ & 0.020 \\
\hline $\mathrm{HbA}_{1} \mathrm{C} \geq 8.5 \%$ & $24(26.1)$ & $31(57.4)$ & $55(37.7)$ & \\
\hline
\end{tabular}

Table 3 shows the mean values of self-care subscales in food secure and food insecure groups. Following a healthy diet and doing regular physical activity was significantly higher in the food secure group than in the food insecure group. However, the overall self-care score was not significantly different between the two groups.

Table 3

.Association between food insecurity and diabetes self-care

\begin{tabular}{|lllll|}
\hline \multicolumn{5}{|c|}{ SD \pm Mean } \\
Characteristics & Food security & Food insecurity & Total & $P^{*}$ \\
\hline Follow a healthy diet & $15.2 \pm 3.6$ & $11.8 \pm 5.2$ & $13.9 \pm 4.4$ & 0.027 \\
\hline Blood sugar monitoring & $2.9 \pm 3.5$ & $4.1 \pm 2.4$ & $3.3 \pm 3.2$ & 0.365 \\
\hline Medication adherence & $5.89 \pm 1.35$ & $5.51 \pm 2.1$ & $5.07 \pm 2.6$ & 0.073 \\
\hline Exercise & $5.9 \pm 4.6$ & $4.82 \pm 3.9$ & $5.02 \pm 3.5$ & 0.040 \\
\hline Foot care & $6.1 \pm 4.3$ & $5.9 \pm 4.1$ & $6.1 \pm 3.8$ & 0.106 \\
\hline Total score & $36.58 \pm 11.7$ & $30.43 \pm 13.6$ & $34.5 \pm 16.5$ & 0.681 \\
\hline * Independent sample t test & & & \\
\hline
\end{tabular}


Table 4 shows the relationship between poor glycemic control ( $\mathrm{HbA} 1 \mathrm{c} \geq 8.5 \%)$ and food insecurity using logistics regression tests. With increasing degrees of food insecurity, the probability of poor glycemic control increased. In the crude model, poor glycemic control had a significant direct association with moderate and severe insecurity (OR: 1.15; $\mathrm{Cl}: 0.74-1.35$ and OR: 2.30; $\mathrm{Cl}$ : 0.62-2.63; respectively). However, after adjustment for confounders, only the association between severe insecurity and poor glycemic control remained significant (OR: 3.02; Cl: 1.45-2.65).

Table 4

Association between food insecurity and poor glycemic control at type 2 diabetes patients

\begin{tabular}{|lllllll|}
\hline Characteristics & \multicolumn{7}{c|}{ Unadjusted } & \multicolumn{5}{c|}{ Fully adjusted * } \\
\cline { 2 - 8 } & $\mathbf{9 5 \% C l}$ & OR & P & $95 \% \mathrm{Cl}$ & OR & P \\
\hline Food security (Reference) & $0.241-0.352$ & 1 & 0.069 & $0.428-0.762$ & 1 & 0.237 \\
\hline Mild Food insecurity & $0.562-1.021$ & 1.004 & 0.149 & $1.037-1.117$ & 0.619 & 0.098 \\
\hline Moderate Food insecurity & $0.741-1.352$ & 1.150 & 0.043 & $1.241-1.374$ & 2.09 & 0.112 \\
\hline Severe Food insecurity & $0.620-2.630$ & 2.309 & 0.001 & $1.453-2.659$ & 3.02 & 0.009 \\
\hline Logistic regression & & & & & & \\
\hline * age, BMI, Marital status, Economic status & & & & & \\
\hline
\end{tabular}

Table 5 shows the relationship between self-care and food insecurity with $\mathrm{HbA} 1 \mathrm{c}$ using linear regression. After adjustment for confounders, it was observed that self-care has a significant inverse relationship with $\mathrm{HbA1c}$ levels $(P=0.016)$ and food insecurity had a direct relationship with $\mathrm{HbA1c}$ levels $(P=0.009)$. That is $\mathrm{HbA} 1 \mathrm{c}$ decrease by 0.68 units given a unit increment in self-care score, and increased by 0.41 units given a unit increment in self-care score.

Table 5

Association of food insecurity and diabetes self-care with $\mathrm{HbA}_{1} \mathrm{C}$

\begin{tabular}{|llll|}
\hline & Beta & $95 \% \mathrm{Cl}$ & P-value* $^{*}$ \\
\hline Self-care score & 0.684 & $0.97-1.47$ & 0.016 \\
\hline Food insecurity & 0.41 & $0.81-1.56$ & 0.009 \\
\hline Linear regression * & & & \\
\hline
\end{tabular}

\section{Discussion}

In this sample of Iranian adults with type 2 diabetes, $37 \%$ of patients were food-insecure. The majority of patients with well-controlled diabetes were food-secure and the majority of patients with poor glycemic 
control had some degrees of food insecurity. On the other hand, there was a significant association between food insecurity and glycemic control. As food insecurity increased, the likelihood of poor glycemic control increased. This association with sever insecurity remained significant after adjustment for confounding factors. In this study, although food security was not significantly associated with overall self-care scores, "following a healthy diet" and "doing regular physical activity" behaviors were significantly higher in the food secure group than in the food insecure group. There was also a significant inverse association between self-care and $\mathrm{HbA1c}$, as well as a positive association between food insecurity and $\mathrm{HbA} 1 \mathrm{c}$.

Findings on the prevalence of food insecurity in diabetic patients referred to Eghlid health center showed that $37 \%$ of households had food insecurity. In a cross-sectional study in Shiraz on 135 newly diagnosed diabetic patients, the prevalence of food insecurity was $66.7 \%$ (32). In a study in Canada, the relationship between food insecurity and diabetes was examined and the results showed that food insecurity was more prevalent among diabetics than non-diabetics (9.3\% vs. 6.8\%) (39). A study by Mohammad Aria et al. showed that the prevalence of food insecurity was $85.3 \%$ in diabetics and $67.1 \%$ in non-diabetics (31). It seems that the reason for the difference in the prevalence of food insecurity in different studies is due to differences in the population in terms of geographical, socio-economic and cultural conditions as well as food habits.

With increasing food insecurity, the probability of poor glycemic control increased. Other studies in this field have also reported a significant association between food insecurity and decreased glycemic control (40-43). Adults with food insecurity provide most of their diet through high-calorie and low-nutrient foods, which diabetic patients are recommended to avoid, such as refined carbohydrates, added sugar and fat. These foods are cheaper than balanced calorie foods such as fruits, vegetables, and dairy products $(44,45)$. People with food insecurity are at risk of diets with less variety, lower quality, lack of micronutrients, and low intake of fruits and vegetables, which can lead to poor glycemic control in diabetics.

In self-care scales, following a healthy diet and doing regular exercise was significantly higher among food secure group than food insecure group, but the overall self-care score was not significantly different between the groups. In some studies, there was no association between food insecurity and diabetes selfcare $(29,46)$. While in some other studies, there was a significant relationship between food insecurity and lack of self-care behaviors $(22,27,47)$.

In the present study, self-care was inversely related to $\mathrm{HbA1c}$ and food insecurity was directly associated with $\mathrm{HbA1c}$. Similar results were found in some other studies (48). Improving self-care behaviors is the first step in helping patients better control their disease. It also emphasizes the design and strengthening of interventions related to self-care behaviors and helps caregivers to better control the patient and reduces the associated complications.

One of the weaknesses of this study is the cross-sectional design of the present study, so we will not be able to interpret the results of this study in the form of a causal relationship. The use of self-administered 
questionnaires is another weakness of this study, and therefore the actual behaviors of patients may not be reported. In this study, we could control for important confounders. Also, using the USDA food security questionnaire, which is one of the best options for measuring household food security, is another strength of this study.

\section{Conclusion}

Results of the present study showed that food-insecurity has a direct association with poor glycemic control in type 2 diabetes patients. On the other hand, food-secure group had higher scores of following healthy diet and physical activity. Since economic status was significantly better in the food-secure group, it can be postulated that financial problems will eventually lead to non-compliance with the recommendations and therefore poor glycemic control. Policy strategies to increase access to diabetesappropriate foods may reduce socioeconomic inequalities in glycemic control.

\section{Declarations}

\section{Ethics approval and consent to participate}

\section{Ethics approval:}

Not applicable. Written consents were obtained from all participants.

\section{Consent for publication}

Not applicable

\section{Availability of data and materials}

Please contact author for data requests

\section{Competing interests}

The authors declare that they had no competing interests

\section{Funding}

This study was supported by Islamic Azad University Science and Research Branch

\section{Authors' contributions}

M.M and A.A-J designed the study, analyzed and interpreted the data, also drafting the manuscript. A.A-J supervised the study and S-A.D revised the manuscript for important intellectual content and final 
approval of the version to be published. All authors approved the final version of manuscript.

\section{Acknowledgements}

The authors wish to acknowledge Eghlid county Health Center for providing Health record.

\section{References}

1. Frongillo EA, Chowdhury N, Ekstrom E-C, Naved RT. Understanding the experience of household food insecurity in rural Bangladesh leads to a measure different from that used in other countries. J Nutr. 2003;133(12):4158-62.

2. Furness BW, Simon PA, Wold CM, Asarian-Anderson J. Prevalence and predictors of food insecurity among low-income households in Los Angeles County. Public Health Nutr. 2004;7(6):791-4.

3. Melgar-Quinonez HR, Zubieta AC, MkNelly B, Nteziyaremye A, Gerardo MFD, Dunford C. Household food insecurity and food expenditure in Bolivia, Burkina Faso, and the Philippines. J Nutr. 2006;136(5):1431S-7S.

4. Sarlio-Lahteenkorva S, Lahelma E. Food insecurity is associated with past and present economic disadvantage and body mass index. J Nutr. 2001;131(11):2880-4.

5. Tarasuk V. Discussion paper on household and individual food insecurity: Valerie Tarasuk; 2001.

6. Nord M, Jemison K, Bickel GW. Measuring Food Security in the United States: Prevalence of Food Insecurity and Hunger, by State, 1996-1998: US Department of Agriculture, Economic Research Service; 1999.

7. Shariff ZM, Lin KG. Indicators and nutritional outcomes of household food insecurity among a sample of rural Malaysian women. J Nutr. 2004;30:50-5.

8. Hakeem R, Asar F, Shaikh A. Food Insecurity in metropolis of the developing world-observations from Central District of Karachi, Pakistan. JOURNAL-PAKISTAN MEDICAL ASSOCIATION. 2003;53(11):556-62.

9. North I. Food insecurity in Canadian households. Health reports. 2001;12(4):11.

10. H G, M K, M K. Food and nutrition security in Tehran Province. National Nutrition and Food Tecnology Research Institute [in Persian]. 1996;2.

11. Martin KS, Rogers BL, Cook JT, Joseph HM. Social capital is associated with decreased risk of hunger. Soc Sci Med. 2004;58(12):2645-54.

12. Vozoris NT, Tarasuk VS. Household food insufficiency is associated with poorer health. J Nutr. 2003;133(1):120-6.

13. Weigel MM, Armijos RX, Hall YP, Ramirez Y, Orozco R. The household food insecurity and health outcomes of US-Mexico border migrant and seasonal farmworkers. J Immigr Minor Health. 2007;9(3):157-69. 
14. Olson CM. Nutrition and health outcomes associated with food insecurity and hunger. J Nutr. 1999;129(2):521S-4S.

15. King H, Aubert RE, Herman WH. Global burden of diabetes, 1995-2025: prevalence, numerical estimates, and projections. Diabetes Care. 1998;21(9):1414-31.

16. Quan H, Fong A, De Coster C, Wang J, Musto R, Noseworthy TW, et al. Variation in health services utilization among ethnic populations. Cmaj. 2006;174(6):787-91.

17. Dixon LB, Winkleby MA, Radimer KL. Dietary intakes and serum nutrients differ between adults from food-insufficient and food-sufficient families: Third National Health and Nutrition Examination Survey, 1988-1994. J Nutr. 2001;131(4):1232-46.

18. Kaiser LL, Melgar-Quiñonez H, Townsend MS, Nicholson Y, Fujii ML, Martin AC, et al. Food insecurity and food supplies in Latino households with young children. J Nutr Educ Behav. 2003;35(3):148-53.

19. Lee JS, Frongillo EA Jr. Nutritional and health consequences are associated with food insecurity among US elderly persons. J Nutr. 2001;131(5):1503-9.

20. Marín-León L, Segal-Corrêa AM, Panigassi G, Maranha LK, Sampaio MdFA, Pérez-Escamilla R. Food insecurity perception in families with elderly in Campinas, São Paulo, Brazil. Cadernos de saude publica. 2005;21(5):1433-40.

21. Seligman HK, Jacobs EA, Lopez A, Tschann J, Fernandez A. Food insecurity and glycemic control among low-income patients with type 2 diabetes. Diabetes Care. 2012;35(2):233-8.

22. Seligman HK, Davis TC, Schillinger D, Wolf MS. Food insecurity is associated with hypoglycemia and poor diabetes self-management in a low-income sample with diabetes. J Health Care Poor Underserved. 2010;21(4):1227.

23. Vijayaraghavan $M$, Jacobs EA, Seligman $H$, Fernandez A. The association between housing instability, food insecurity, and diabetes self-efficacy in low-income adults. J Health Care Poor Underserved. 2011;22(4):1279-91.

24. Lyles CR, Wolf MS, Schillinger D, Davis TC, DeWalt D, Dahlke AR, et al. Food insecurity in relation to changes in hemoglobin A1c, self-efficacy, and fruit/vegetable intake during a diabetes educational intervention. Diabetes Care. 2013;36(6):1448-53.

25. Seligman HK, Laraia BA, Kushel MB. Concerns about the Secondary Data Analysis of the Association between Food Insecurity and Hyperlipidemia in Low-Income NHANES Participants Reply. JOURNAL OF NUTRITION. 2010;140(8):1536-.

26. Seligman HK, Bindman AB, Vittinghoff E, Kanaya AM, Kushel MB. Food insecurity is associated with diabetes mellitus: results from the National Health Examination and Nutrition Examination Survey (NHANES) 1999-2002. J Gen Intern Med. 2007;22(7):1018-23.

27. Seligman HK, Jacobs EA, Lopez A, Sarkar U, Tschann J, Fernandez A. Food insecurity and hypoglycemia among safety net patients with diabetes. Arch Intern Med. 2011;171(13):1204-6.

28. Berkowitz SA, Baggett TP, Wexler DJ, Huskey KW, Wee CC. Food insecurity and metabolic control among US adults with diabetes. Diabetes Care. 2013;36(10):3093-9. 
29. Walters A, Williams JS, Egede LE. The Association between Food Insecurity, Glycemic Control, SelfCare, and Quality of Life in Adults with Type 2 Diabetes. Journal of Health Disparities Research \& Practice. 2016;9.

30. Javadi M, Mohammadpour Asl A, Khodabakhshi A. Assessment of Food Security Status with lipid profile and body mass index in patients with type 2 diabetes. Journal of Biology Today's World. 2016;5(9):169-72.

31. Mohammad A, Majid K, Hosssen HM. The Comparison of Food Insecurity between Patients with Type 2 Diabetes Mellitus and Non-Diabetic Controls Referred to Rural Health Centers in Abadan. Journal of NutritionFasting Health. 2019;7(1):18-25.

32. Najibi N, Dorosty Motlagh A, Sadrzadeh Yeganeh H, Eshraghian M, Daneshi M, Azizi S. Food insecurity status and some associated socioeconomic factors among newly diagnosed patients with type 2 diabetes in Shiraz, 2012. J Arak Univ Med Sci. 2013;16(1):98-106.

33. Ramesh T, Dorosty A, Abdollahi M. Prevalence of food insecurity in household of Shiraz and association with some of socioeconomic and population factors. Iranian Journal of Nutrition Sciences Food Technology. 2010;4(4):53-64.

34. Ostadrahimi A, Mahboub S, Totonchi H, Dastgiri S, Dadgar L. Prevalence rate and range of food insecurity of two dimension visible and nonvisible hungry in asadabad, tabriz. Research Journal of Lorestan University of Medical Sciences. 2007;8(1):61-6.

35. Bickel G, Cristofer P, William H, John C. Guide to Measuring Household Food Security, Revised March 2000. 2000.

36. Hakim S, Dorosty AR, Eshraghian M. Association of food insecurity and household socio-economic status with the body mass index among urban women in Dezful. Journal of School of Public Health Institute of Public Health Research. 2010;8(2):55-66.

37. Toobert DJ, Hampson SE, Glasgow RE. The summary of diabetes self-care activities measure: results from 7 studies and a revised scale. Diabetes Care. 2000;23(7):943-50.

38. Anbari Kh, Ghanadi K, Kaviani M, Montazeri R. The self care and its related factors in diabetic patients of khorramabad city. yafte. 2012;10(4):49-57.

39. Gucciardi E, Vahabi M, Norris N, Del Monte JP, Farnum C. The Intersection between Food Insecurity and Diabetes: A Review. Current Nutrition Reports. 2014;3(4):324-32.

40. Holben DH, Pheley AM. Peer Reviewed: Diabetes Risk and Obesity in Food-Insecure Households in Rural Appalachian Ohio. Preventing chronic disease. 2006;3(3).

41. Bawadi HA, Ammari F, Abu-Jamous D, Khader YS, Bataineh Sa, Tayyem RF. Food insecurity is related to glycemic control deterioration in patients with type 2 diabetes. Clin Nutr. 2012;31(2):250-4.

42. Berkowitz SA, Meigs JB, DeWalt D, Seligman HK, Barnard LS, Bright O-JM, et al. Material need insecurities, control of diabetes mellitus, and use of health care resources: results of the Measuring Economic Insecurity in Diabetes study. JAMA internal medicine. 2015;175(2):257-65.

43. Homenko DR, Morin PC, Eimicke JP, Teresi JA, Weinstock RS. Food insecurity and food choices in rural older adults with diabetes receiving nutrition education via telemedicine. J Nutr Educ Behav. 
2010;42(6):404-9.

44. Bharati D, Pal R, Rekha R, Yamuna T. Evaluation of the burden of type 2 diabetes mellitus in population of Puducherry, South India. Diabetes \& Metabolic Syndrome: Clinical Research \& Reviews. 2011;5(1):12 - 6 .

45. Molly G, Mahan L, Scott-Stump S. Weight management. Krause's food and nutrition therapy. 12th ed. ED Philadelphia: WB Saunders; 2008. pp. 532-62.

46. Gucciardi E, Vogt JA, DeMelo M, Stewart DE. Exploration of the relationship between household food insecurity and diabetes in Canada. Diabetes Care. 2009;32(12):2218-24.

47. Heerman W, Wallston K, Osborn C, Bian A, Schlundt D, Barto S, et al. Food insecurity is associated with diabetes self-care behaviours and glycaemic control. Diabet Med. 2016;33(6):844-50.

48. Mahmoodi A, Alavi M. Mosavi. N. The Relationship between Self-Care Behaviors and HbA1c in Diabetic Patients. Avicenna J Nurs Midwifery care. 2012;20:20-30. 